\title{
Application of Binomial Models on the Determinants of Hypertension Patients in Haramaya Woreda, Eastern Hararghe, Ethiopia
}

Kindu Kebede ( $\sim$ m7.kebede@gmail.com )

Haramaya University

Murad Mohammed

Haramaya University

Million Wesenu

Haramaya University

\section{Research}

Keywords: hypertension, binomial model, diabetes mellitus, Hospital

Posted Date: December 28th, 2021

DOI: https://doi.org/10.21203/rs.3.rs-1189281/v1

License: (c) (i) This work is licensed under a Creative Commons Attribution 4.0 International License.

Read Full License 


\section{Abstract}

Introduction: Hypertension is along with a medical condition, in which the blood pressure in the arteries is high, which is a major health problem in the community. The main aim of the study was to assess the determinants associated with patients who experienced hypertension in Haramaya Woreda using a binomial model.

Methods: A cross-sectional study design was conducted to assess the associated factors of hypertension patients' complications in the Haramaya Hospital, Eastern Hararghe zone from December $7^{\text {st }}$ to 30th, 2020. Data were statistically analyzed using the statistical package for social sciences (SPSS) version-23 (SPSS Inc., USA). A sample of 1417 respondents having hypertension chronic disease was included. Statistical tools such as descriptive statistics, chi-square test of association, and binomial regression were used to summarize and interpret the hypertension patients' dataset and a $5 \%$ level of significance was also used as a baseline comparison.

Results: Both chi-square test of association and binomial model revealed that age group, gender, residence, presence of diabetes mellitus and congestive heart failure were significantly associated with hypertension patients at a $5 \%$ level of significance. Multivariable binomial regression model indicated that an estimated odd ratio(OR) with $95 \%$ confidence interval were age group of 2130 year3.502(95\% Cl=1.310-9.361),31-40year6.108(95\% Cl=2.364-15.782),41-50year $11.070(95 \% \mathrm{Cl}=4.276$ $28.661), 51-60$ year $12.530(95 \% \mathrm{Cl}=4.890-32.107)$ and greater than 60 years $12.713(95 \% \mathrm{Cl}=4.827-$ 33.482), being male $(\mathrm{OR}=1.859 ; 95 \% \mathrm{Cl}=1.320-2.617)$, living in rural $(\mathrm{OR}=0.545 .95 \% \mathrm{Cl}=0.381-0.778)$. The presence of diabetes mellitus ( $\mathrm{OR}=0.028,95 \% \mathrm{Cl}=0.019-0.040)$, and congestive heart failure ( $\mathrm{OR}=0.017$, $95 \% \mathrm{Cl}=0.009-0.032)$ are associated risk factors of hypertension patients.

Conclusions: The main hypertension risk factors were age category, gender, residence, having diabetes mellitus, and congestive heart failure $(p=0.0001)$. Those were significantly associated with hypertension in both the chi-square test of association and binomial model. To predict the participants being a hypertensive binomial model with logit link function best fit the dataset.

\section{Introduction}

Hypertension is a long-term medical condition in which the blood pressure in the arteries is high. Hypertension is a chronic health disorder characterized by higher blood pressure (BP) in the blood vessel and determined as raised systolic blood pressure $\geq 140 \mathrm{mmHg}$ or diastolic blood pressure $\geq 90 \mathrm{mmHg}$ in adults aged 18 years and above\{Animut, 2018 \#4;Asresahegn, 2017 \#2;Legese, 2020 \#5\} [1]-[4]. Longterm high blood pressure is a major risk factor for coronary artery disease, stroke, heart failure, atrial fibrillation, peripheral arterial disease, vision loss, chronic kidney disease, and dementia. Blood pressure is expressed by two measurements such as systolic and diastolic pressures, which are the maximum and minimum pressures, respectively. High blood pressure is divided into primary hypertension or secondary hypertension. About 90 up to $95 \%$ of cases are primary, defined as high blood pressure due to nonspecific 
lifestyle and genetic factors. On average, systolic and diastolic blood pressures were $125.3 \mathrm{mmHg}$ and $78.5 \mathrm{mmHg}$, correspondingly [5].The average systolic and diastolic blood pressure respectively were $117.0 \mathrm{mmHg}$ and $75.5 \mathrm{mmHg}[6]$.

Hypertension is the top leading cause of the global burden of disease [7]. Because of its associated risks of cardiovascular and kidney diseases such as myocardial infarctions, strokes, and renal failures as well as its frequent disease, hypertension disease is the main health challenge in the community[1]. Hypertension affects around $22 \%$ of people aged 18 years and above and it is responsible for an estimated 9.4 million deaths per year globally [8], [9]. ]. Hypertension is a worldwide public health problem and it is a risk factor for cardiovascular disease. An estimated 1.13 billion people worldwide have hypertension, most (two-thirds) living in low- and middle-income countries [10].

According to World Health Organization, African Region has the highest prevalence of hypertension (27\%) while the American Region has the lowest prevalence of hypertension (18\%) [10].The increasing prevalence of hypertension in developing countries is a major concern. According to recent estimates from the World Health Organization, two-thirds of hypertensive people live in developing countries including Ethiopia [11]. Hypertension is the leading risk factor for cardiovascular disease and death in Africa. It is a public health problem and big economic impact in Africa. This is because a significant proportion of the productive population is affected by hypertension and its complications[12]. Almost three-quarters of people with hypertension live in developing countries where people have very low awareness of hypertension [13]. The prevalence of hypertension is increasing in Africa rising from $19.7 \%$ in 1990 to $30.8 \%$ in 2010 [14].

A review of current trends shows that the number of adults with hypertension increased from 594 million in 1975 to 1.13 billion in 2015, with the increase seen largely in low and middle-income countries. The lower-income countries include Ethiopia have been affected by double burden diseases. The WHO 2011 report showed that $34 \%$ of all deaths in Ethiopia were due to non-communicable diseases, from which cardiovascular disease contributes 15\% [15]. Burial surveillance in Addis Ababa also revealed that $51 \%$ of all deaths were due to non-communicable diseases, of which cardiovascular disease was a main cause of death (24\%), and hypertension was responsible for $12 \%$ of the cardiovascular disease deaths [16].

Some studies have been done on hypertension that swept the worldwide. According to the World Health Organization's recent update [9], hypertension is one of the top five continuing risk factors for cardiovascular deaths in the world. The World Health Organization (WHO) predicted deaths from noncommunicable diseases (NCDs) would increase globally by $17 \%$ over the next ten years where the greatest increase will be in the African region (by $27 \%$ or 28 million deaths from NCDs)[17]. Raised blood pressure is the principal risk factor for worldwide mortality in which 9.4 million deaths and $7 \%$ of disease burden in 2010 were caused by elevated blood pressure. If blood pressure is left uncontrolled, hypertension causes stroke, myocardial infarction, cardiac failure, dementia, renal failure, and blindness [1]. Concerning the deviations in regional and residence adults with hypertensive were $40 \%$ in the world and $46 \%$ in Africa [18]-[20]. Regarding the problem with hypertension disease, the peoples are not 
responsive to their health status to the timely and suitable intervention, the symptoms of the disease do not appear until complications of a heart attack happen, developed severe disabilities like heart failure, chest pain, and irregular heartbeat which leads to sudden death in many guys with elevated blood pressure[4].

According to World Health Organization, the method that discourses treatment decisions relied on individual risk factors is less cost-effective than the technique that addresses total cardiovascular risk [21], [22].World Health Organization recommends a total risk tactic that enables assimilated control of hypertension, diabetes, and other cardiovascular risk factors in primary care and targets available resources at persons most likely to develop heart attacks, strokes, and diabetes complications [15], [23]

Diabetes contributes a huge burden of disease so that diabetic patients exhibit a very high prevalence of hypertension. People have a high prevalence of hypertension that is three times more affected than the general population[24].According to the study done in sub-Saharan Africa, as a result of diabetes, the total disability-adjusted life years were increased by 126.4\% between 1990 and 2017, thus, the decide largest change observed across all level 3 causes of NCD burden. Diabetes in sub-Saharan Africa has not only increased in terms of total disability-adjusted life years, but also in terms of crude and agestandardized disability-adjusted life year rates, as well as years of life lost and years of life lived with disability rates [25]. Diabetes status was a significant risk factor as evidenced by the prevalence of hypertension among $29.9 \%, 44.0 \%$, and $53.3 \%$ for normoglycemic, prediabetes, and diabetic individuals, respectively [26]. The residence status of the patient was found to have a significant factor of hypertension among its prevalence that 33.5\% for Atbara, 39.5\% for Ed Damer, 30.4\% for Shendi, and $41.0 \%$ for berber[26]. The study conducted by Huang et al., (2020) reported that compared with nonhypertensive patients, hypertensive patients were older (58-73 vs 40-68), had higher rates of diabetes ( $28.3 \%$ vs $8.1 \%)$, and had a higher mortality rate ( $24.8 \%$ vs $15.2 \%)$. Different studies in Ethiopia and others revealed that increased risk of hypertension was associated with older age ( $>=45$ years), obesity[28], smoking [29] and chat chewing [29], [30].

In spite of the fact that several studies have been done on hypertension using a summary measure of statistics, meta-analysis to predict the effect of associated factors by ignoring the covariates are at the level of the study rather than the level of the subject, and the dependent variable is the effect size in the studies rather than subject scores. An up-to-date and comprehensive assessment of the evidence concerning hypertension in Ethiopia is lacking. Thus, this study assessed associated factors of Hypertension patients and the application of Binomial models in Haramaya Woreda, Eastern Hararghe, and Ethiopia.

\section{Methods}

\subsection{Study Design, and Period}


A cross-sectional study design was conducted to investigate the factors associated with hypertension patients' complications in Haramaya Hospital, Eastern Hararge Zone, Ethiopia. Haramaya hospital is one of the public hospitals in the East Hararge zone which is found in Ethiopia and was established in 2000. The admitted hypertension patients and related health complaints were deliberated as hospital admission due to high hypertension complications. All patients admitted to the medical ward of the hospital from January 1st, 2019 to December 30th, 2020 due to hypertension-related health conditions such as stroke, cardiovascular, renal, or peripheral vascular diseases, and hypertensive emergencies were included in this study. However, patients with those health conditions and additional comorbidities such as diabetes mellitus, and patients with $<140 / 90 \mathrm{mmHg}$ blood pressure at admission or with no documented antihypertensive medication history were excluded from this study.

\subsection{Data Sources and Collection Procedures}

Hypertension was defined as admission blood pressure of $\geq 140 \mathrm{mmHg}$ systolic and/or $\geq 90 \mathrm{mmHg}$ diastolic or previously on anti-hypertension medication. Blood pressure was measured by the physician or nurse at the emergency department using a standard mercury sphygmomanometer. Patients were allowed to sit for 5 minutes before measurement then at least two blood pressure measurements; spaced 1-2 minutes apart were taken. This was repeated every 30 minutes until the patient gets stable per the national guideline [31]. We took the average of the first two consecutive records as the patient's blood pressure at admission. We considered the type of hypertension complication recorded on the patient discharge notes as the final diagnosis of hypertension complication.

Data were collected through reviewing medical records; admission logbooks and patient folders by the investigation team using a data extraction sheet. First, we reviewed medical admission logbooks to count the sex and admission outs of all medically admitted patients and to identify and prepare the list of Unique Medical Record Number (UMRN) of 1417 patients admitted due to hypertension complications. Then, using patients' UMRN those patient folders were drawn from the medical record room and reviewed for data collection. Data retrieved from patient and tuberculosis screening results.

\subsection{Variables of the study}

Dependent Variables of the study: The dependent variable is hypertension complication that coded as 1 for the presence of hypertension complication and 0 for the absence of hypertension complication.

Independent variables of the study: The independent variables were age group sex, residence, diabetes mellitus, congestive heart failure, and tuberculosis screening results.

\subsection{Operational Definition of the terms}

Hypertension is a higher blood pressure that determined as raised systolic blood pressure $\geq 140 \mathrm{mmHg}$ or diastolic blood pressure $\geq 90 \mathrm{mmHg}$ [1], [3], [4].

Diabetes mellitus is a group of metabolic diseases in which there are high blood sugar levels over a prolonged period This high blood sugar produces the symptoms of frequent urination, increased thirst, 
and increased hunger [32].

Heart failure is a chronic, progressive condition in which the heart muscle is unable to pump enough blood to meet the body's needs for blood [33] .

Congestive heart failure is a type of heart failure that requires seeking timely medical attention, although sometimes the two terms are used interchangeably.

Tuberculosis screening results is defined as the identification of people with suspected active TB, in a predetermined target group, using tests, examinations or other procedures that can be applied rapidly [34].

\subsection{Methods of Data Collection and Data Analysis}

The collected data were checked for completeness and consistency daily by principal investigators. The data was entered into SPSS version 23 statistical software for analysis.

\subsection{Specification of Binomial regression model}

This model describes the relationship between a dichotomous response variable and a set of continuous or discrete explanatory variables [35]. The logistic regression model has become the statistical model of choice [36]. First, it considers the case where the response variable $y_{i}$ is binary, assuming only two values that are coded as one or zero.

$y_{i}=\left\{\begin{array}{rr}1, & \text { if the } \mathrm{i}^{\text {th }} \text { patients with hypertension } \\ 0, & \text { if the } \mathrm{i}^{\text {th }} \text { patients without hypertension }\end{array}\right.$

We view $\mathrm{y}_{\mathrm{i}}$ as a realization of a random variable $\mathrm{Y}_{\mathrm{i}}$ (hypertension complication) that can take the values one and zero with probabilities $\Pi_{\mathrm{i}}$ and $1-\Pi_{\mathrm{i}}$, respectively.

The Binomial Regression model is the family of Generalized Linear Models. GLMs are used to model the relationship between the expected value of a response variable $y$ and a linear combination of the explanatory variables vector $X$ using link function such as logit and probit.

Odds ratio of binary logistic regression: The logistic regression function can be expressed in terms of odds ratio.

$$
\frac{\pi_{\mathrm{i}}}{1-\pi_{\mathrm{i}}}=\exp \left\{\mathrm{x}_{\mathrm{i}}^{\prime} \beta\right\}
$$

This expression defines a multiplicative model for the odds. For instance, if we were to change the $j^{\text {th }}$

predictor by one unit while holding all other variables constant, we would multiply the odds by $\exp \left\{\boldsymbol{\beta}_{j}\right\}$. Following some algebraic manipulation, the following intrinsically linear function is produced. 
$\ln \left[\frac{\pi_{\mathrm{i}}}{1-\pi_{\mathrm{i}}}\right]=\mathrm{x}_{\mathrm{i}}^{\prime} \beta=\beta_{0}+\beta_{1} \mathrm{x}_{1}+\beta_{2} \mathrm{x}_{2}+\ldots . .+\beta_{\mathrm{k}} \mathrm{x}_{\mathrm{k}}$

\subsection{Parameter Estimation and Model Diagnosis}

Logistic regression uses a maximum likelihood estimation technique to estimate parameters in the model. Maximum likelihood function yields the best solution for the binary logistic model and log likelihood function are given in Equations (4) and (5), respectively (Anthony et al, 2014).

$$
\mathrm{L}\left(\beta \left(=\prod_{\mathrm{i}=1}^{\mathrm{n}}\left(\pi_{\mathrm{i}}\right)^{\mathrm{y}_{\mathrm{i}}}\left(1-\pi_{\mathrm{i}}\right)^{1-\mathrm{y}_{\mathrm{i}}}\right.\right.
$$

$$
\ln L\left(\beta n=\sum y_{i} \ln \left(\pi_{i}\right)+\left(1-y_{i}\right) \ln \left(1-\pi_{i}\right)\right.
$$

The well fitted models show non-significance on the Hosmer and Lemeshow goodness-of fit test. This desirable outcome of non-significance indicates that the model prediction does not significantly differ from the observed [38].To test the capability of all predictors in the model jointly to predict the response variable. A finding of significance of Omnibus test corresponds to concluding that there is adequate fit of the data to the model [38].

\section{Results}

\subsection{Distributions and summary measures of categorical variables in the study}

The outline measures of socio-economic factors were displayed in Table 1. The whole tests of 1417 hypertension patients conceded to Haramaya Clinic were utilized to recognize the potential factors and utilized binomial models. Out of the whole, $58.0 \%$ ( 822) of male patients were conceded to the healing center for hypertension screening though $42.0 \%$ (595) were female patients. More of the patients were living in rustic ranges $65.8 \%$ (932) of Haramaya woreda. The respondents have categorized age dispersions of $14 \%(198)$ for $21-30,21.4 \%$ (303) for $31-40,20.2 \%(286)$ for $41-50,21.5 \%(305)$ for $51-60$, and $14.0 \%$ (199) for more than 60 a long time though the remaining $8.9 \%$ have less than twenty years old. Patients who experienced diabetes mellitus within the clinic were around $55.5 \%$ of the entire affirmation and $44.5 \%$ did not have diabetes.

Inlined with this tall rate of diabetes patients the chi-square test of affiliation appeared that there's a measurable affiliation between those persistent maladies of hypertension and diabetes ( $p$ value $=0.00001$ ). Most of the patients with hypertension were not experienced congestive heart disappointment $81.5 \%$ (1155) and had negative Tuberculosis screening comes about $94.3 \%(1336)$. Be 
that as it may, around $18.5 \%$ (262) of the patients had congestive heart disappointment unremitting illnesses which have a solid affiliation with hypertension.

The comes about of the chi-square test of affiliation shown in Table 1 uncovered that Age group, sex, Home, nearness of diabetes mellitus, and congestive heart disappointment were altogether related to the hypertension patients at a five percent level of noteworthiness. This suggests the nearness of those components deciding the presentation hazard of the encompassing community for the unremitting hypertension illness in Haramaya Woreda. In expansion, the age dispersion of respondents appeared that more of the patients were in Age category of 41-50 and 51-60 a long time as shown in Figure1. But Tuberculosis has no such impact on the hypertension patients of the clinic conceded within the current study.

Table 1

Distributions and summery measures of determinants associated with Hypertension patients'

\begin{tabular}{|lllllll|}
\hline Variables & Category & Frequency & Percentage & Statistic & Df & p-value \\
\hline Age group & $<=20$ & 126 & 8.9 & 45.419 & 5 & 0.00001 \\
& $21-30$ & 198 & 14.0 & & & \\
& $31-40$ & 303 & 21.4 & & & \\
& $41-50$ & 286 & 20.2 & & & \\
& $51-60$ & 305 & 21.5 & & & \\
& $>60$ & 199 & 14.0 & & & \\
\hline Gender & Male & 822 & 58.0 & 43.309 & 1 & 0.00001 \\
& Female & 595 & 42.0 & & & \\
\hline Residence & Urban & 485 & 34.2 & 14.258 & 1 & 0.00001 \\
& Rural & 932 & 65.8 & & & \\
\hline Presence of DM & Non-diabetic & 631 & 44.5 & 262.396 & 1 & 0.00001 \\
& Diabetic & 786 & 55.5 & & & \\
\hline Congestive heart failure & No & 1155 & 81.5 & 77.981 & 1 & 0.00001 \\
& Yes & 262 & 18.5 & & & \\
\hline TB screening result & Negative & 1336 & 94.3 & 0.204 & 1 & 0.6520 \\
& Positive & 81 & 5.7 & & & \\
\hline
\end{tabular}

Most of the hypertensive patients were found in Age bunch of 51-60 a long time while youthful age bunches of less than 20 a long time were less uncovered to be hypertensive as demonstrated in Figure 1. 


\subsection{Classification of Hypertension patients' data}

A classification Table 2 was used to summarize the predictive power of a binary logistic model. In this case, the Table cross-classifies the binary response with a prediction of whether respondents were not experienced hypertension $(y=0)$ or had experienced hypertension $(y=1)$. Therefore, the predictive power of the binary logistic regression model for hypertension patients being correct classification was $88.0 \%$ based on the cutoff value of 0.5 .

Table 2

Classification of hypertension patients.

\begin{tabular}{|c|c|c|c|c|c|}
\hline \multicolumn{3}{|c|}{ Observed } & \multicolumn{3}{|c|}{ Predicted } \\
\hline & & & \multicolumn{2}{|c|}{ Hypertension } & \multirow[t]{2}{*}{ Percentage Correct } \\
\hline & & & No & Yes & \\
\hline \multirow[t]{3}{*}{ Step 1} & \multirow[t]{2}{*}{ Hypertension } & No & 972 & 73 & 93.0 \\
\hline & & Yes & 97 & 275 & 73.9 \\
\hline & \multicolumn{2}{|c|}{ Overall Percentage } & & & 88.0 \\
\hline
\end{tabular}

\subsection{Link function for Model Comparison and Model Summary}

Model selection was done using Akaike information criteria and comparisons have been made between the link function of logit, probit, and identity. Based on the result of the generalized linear model with the respective link function, binary logistic with logit link function has the smallest Akaike information criteria $(A I C=267.102)$ and Bayesian information criteria $(B I C=324.932)$ among the candidate model which implies that model with logit link function best fit of the hypertension dataset. In addition, loglikelihood and deviance statistics are also inlined with the logit link function of binary logistic regression as observed in Table 3.

Table 3

Model comparison for hypertension dataset.

\begin{tabular}{|llllll|}
\hline Link function & Df & AIC & BIC & Log Likelihood & Deviance \\
\hline Identity & 10 & 813.625 & 876.701 & -394.812 & 144.846 \\
\hline Logit & 10 & 267.102 & 324.922 & -122.551 & 112.253 \\
\hline Probit & 10 & 269.885 & 327.704 & -123.942 & 115.036 \\
\hline
\end{tabular}




\subsection{Result of Final binomial regression model and Interpretations of Parameter}

Parameter estimates and their corresponding confidence interval of $95 \%$ for odds ratio were presented in Table 4. The binomial logistic regression with logit link function results indicated that age, gender, living place(residence), presence of diabetes mellitus, and congestive heart failure were significantly associated with being hypertensive of patients in the Haramaya woreda community whereas the Tuberculosis screening result was insignificant at $5 \%$ level of significance. The odds of hypertensive patients being female was 1.859 times more likely to be exposed to chronic hypertension disease as compared to male respondents of the hospital admitted patients. This implies about $85.9 \%$ of female respondents in the haramaya woreda were experienced hypertension complication's than males $(\mathrm{OR}=1.859 ; 95 \% \mathrm{Cl}=1.320$ 2.617). The Wald-test results for Age group of hypertension patients showed at least one coefficient different from zero which reflected that Age group had a significant effect on hypertension patients' of the community. Being older Age in years increased the risk of having hypertension complications. An estimated odd of hypertensive patients among Age group of 21-30, 31-40, 41-50, 51-60 and greater than 60 years were $3.502(95 \% \mathrm{Cl}=1.310-9.361), 6.108(95 \% \mathrm{Cl}=2.364-15.782), 11.070(95 \% \mathrm{Cl}=4.276-28.661)$, $12.530(95 \% \mathrm{Cl}=4.890-32.107)$ and $12.713(95 \% \mathrm{Cl}=4.827-33.482)$ respectively. As a result, the risk of being hypertensive was more than three-fold for 21-30 years, six-fold for 31-40 years, eleven-fold for 41-50 years, and more than 12 fold for greater than 50 years higher as compared to their counterparts.

Another important factor was the Residence of respondents which is potentially affecting the hypertension patients in the surrounding. An estimated odds of living in rural area was $45.5 \%$ times less likely to develop hemoglobin complications' than being resident in urban $(\mathrm{OR}=0.545 .95 \% \mathrm{Cl}=0.381$ 0.778). In addition, respondents having diabetes mellitus ( $\mathrm{OR}=0.028,95 \% \mathrm{Cl}=0.019-0.040)$ and congestive heart failure $(\mathrm{OR}=0.017,95 \% \mathrm{Cl}=0.009-0.032)$ were less developed hypertension chronic disease than those who haven't Diabetes and heart failure Respectively as indicated in Table 4. The goodness model has been checked using the Hosmer and Lemeshow test which suggested that the binomial model of logit link function was an appropriate model to predict and analyze the hypertensive patients' data set (chi-sq=11.00, P-value=0.202). 
Table 4

Results of final binomial model with logit link function parameter estimation.

\begin{tabular}{|c|c|c|c|c|c|c|c|c|}
\hline Factors & Levels & $\beta$ & SE & Wald & Df & p-value & AOR & $\begin{array}{l}\text { 95\%Cl.for } \\
\text { AOR }\end{array}$ \\
\hline \multirow[t]{6}{*}{ Age group $(<=20)$} & $21-30$ & 1.253 & 0.502 & 6.242 & 1 & 0.0120 & 3.502 & \multirow{2}{*}{$\begin{array}{l}{[1.310-} \\
9.361]\end{array}$} \\
\hline & $31-40$ & 1.810 & 0.484 & 13.960 & 1 & 0.00001 & 6.108 & \\
\hline & $41-50$ & 2.404 & 0.485 & 24.536 & 1 & 0.00001 & 11.070 & $\begin{array}{l}{[2.364-} \\
15.782]\end{array}$ \\
\hline & $51-60$ & 2.528 & 0.480 & 27.734 & 1 & 0.00001 & 12.530 & $\begin{array}{l}{[4.276-} \\
28.661]\end{array}$ \\
\hline & $>60$ & 2.543 & 0.494 & 26.486 & 1 & 0.00001 & 12.713 & $\begin{array}{l}{[4.890-} \\
32.107]\end{array}$ \\
\hline & & & & & & & & $\begin{array}{l}{[4.827-} \\
33.482]\end{array}$ \\
\hline Gender (male) & Female & 0.620 & 0.175 & 12.606 & 1 & 0.00001 & 1.859 & $\begin{array}{l}{[1.320-} \\
2.617]\end{array}$ \\
\hline Residence(urban) & Rural & -0.608 & 0.182 & 11.154 & 1 & 0.0010 & 0.545 & $\begin{array}{l}{[0.381-} \\
0.778]\end{array}$ \\
\hline $\begin{array}{l}\text { Diabetes } \\
\text { mellitus(no) }\end{array}$ & Yes & -3.591 & 0.192 & 349.306 & 1 & 0.00001 & 0.028 & $\begin{array}{l}{[0.019-} \\
0.040]\end{array}$ \\
\hline $\mathrm{CHF}(\mathrm{No})$ & Yes & -4.098 & 0.329 & 154.746 & 1 & 0.00001 & 0.017 & $\begin{array}{l}{[0.009-} \\
0.032]\end{array}$ \\
\hline $\begin{array}{l}\text { TB screening } \\
\text { (No) }\end{array}$ & Yes & 0.013 & 0.366 & 0.001 & 1 & 0.9720 & 1.013 & $\begin{array}{l}{[0.494-} \\
2.076]\end{array}$ \\
\hline Intercept & & -0.743 & 0.477 & 2.425 & & 0.119 & 0.476 & \\
\hline
\end{tabular}

\section{Discussion}

This study was aimed to identify and describe factors associated with hypertension patients' using the binomial model in Haramaya Woreda of East hararghe zone, Ethiopia. The results of the study implied that out of the sample 1417 of hypertensive patients admitted at Haramaya hospital from January 1 st, 2019 to December 30th, 2020, 26.3\% were experienced hypertension while 73.7\% were not hypertensive.

The study revealed that Age of patients', gender, Residence, presence of diabetes mellitus, and congestive heart failure had a significant effect on being hypertensive of respondents who live in Haramaya woreda that admitted to Haramaya Hospital at a $5 \%$ level of significance. The binomial model was employed with logit, probit, and identity link function, and the model with logit link function was an appropriate model based on Akaike information criteria which had the smallest $(\mathrm{AIC}=267.102)$ value as compared to 
candidates' models. Hosmer and Lemeshow test also indicated that the binomial model with logit link function was a good fit for the hypertensive dataset. The prevalence for hypertension patients was $26.3 \%$.

Both chi-square test of association and binomial model showed age group of patients $\backslash$ had a significant effect on being hypertensive. The risk of respondents experiencing hypertension was increased as the Age of patients increased. As a result, the risk of being hypertensive was more than three-fold for 21-30 years, six-fold for 31-40 years, eleven-fold for 41-50 years and more than 12 fold for greater than 50 years higher as compared to younger age. This study consistent with study done by [39]-[41]. As the age increased for the patients the incidence risk of disease also increased which is in-lined with [13], [42], [43]. Another important factor associated with hypertensive was Gender of respondents which had significant effect on hypertension patients at $5 \%$ level of significance. The parameter estimation of binomial model indicated that the odds of female gender associated to being hypertensive was increased 1.859 times more as compared to counterpart. This implies females were more vulnerable part of society with hypertension disease in Haramaya Woreda and there was positive association between gender and being hypertensive. This study confirmed with study done in Nepal [13], [44]. Also study done in Debre Markos Town supported that being female was associated with hypertensive [20].

Living place of patients had effect to experience chronic hypertension based on the dataset of haramaya hospital. As a result of binomial model, the estimated risk of rural residence was 0.545 with confidence interval of $95 \%$ [0.381-0.778]. The risk of living in rural was 0.545 less likely to develop hypertension as compared living in urban area. This may be as a reason of most rural resident exercise more due to working on agricultural practice and used iron lacked food. The result linked with study conducted in Addis Ababa, Ethiopia, which indicated that Rural residents had a 3.5\% lesser risk of death than urban patients [45].

Other important factors were presence of chronic disease diabetes mellitus and congestive heart failure which is significantly associated with being hypertensive. The odd of having diabetes mellitus was $2.8 \%$ less likely to develop hypertension than non-diabetes patients in the Haramaya woreda residents. This implies being admitted for diabetes mellitus treatment at hospital deceased the risk of developing chronic disease hypertension or non-diabetes people had more probability of exposed to hypertension disease in the community. The reason may be the health complication of diabetes was treated in the way that it decreases the risk of hypertensive person. Congestive heart failure also has significant effect on the respondents being hypertensive.

\section{Conclusions}

The prevalence of chronic hypertension was $26.3 \%$ among the study participants. Age category of respondents, gender, residence, having diabetes mellitus and congestive heart failure were independent predictors of hypertension. To predict and estimate the parameters of participants being hypertensive binomial model with logit link function was an appropriate model as the result of Hosmer and lemeshow statistic indicated $\left(\chi^{2}=11.00, p\right.$-value $\left.=0.202\right)$. The healthcare providers are recommended to give due 
attention for older age, women, urban resident and serious care for participants having diabetes mellitus and congestive heart failure in order to minimize the occurrence of hypertensive. On the top of this, future planning should be turn face to trainee the health services professional.

\section{Declarations}

\section{Ethics approval and consent to participate}

Letter of ethical clearance was obtained from Haramaya University, Department of Statistics and submitted to Haramaya Hospital to get permission to conduct this research. This study was developed in accordance with established legislation and complies with the norms of good clinical practice, and informed consent was being not necessary as personal identifying information was kept separate from this research data. Finally, the study protocol was approved by the ethics committee or medical directors of the Hospital.

\section{Consent for publication}

Not Applicable

\section{Availability of data and materials}

The raw data used in this study can be accessed from Haramaya Hospital.

\section{Competing interests}

The authors declare that they have no competing interests.

\section{Funding}

This Research has no fund.

\section{Authors' contributions}

$\mathrm{KK}, \mathrm{MM}$ and $\mathrm{MW}$ was involved in the conception and design of the study, drafting the manuscript, review of protocol development, interpretation of the data and review of the manuscript. All authors read and approved the final manuscript.

\section{Acknowledgments}

The authors express sincere gratitude to all colleagues working at Haramaya University for giving constructive idea for the success of this study. Also, the authors are grateful for the data collectors and study participants.

\section{References}


1. S. Marrero and E. Y. Adashi, "Noncommunicable diseases," Semin. Reprod. Med., vol. 33, no. 1, pp. 35-40, 2015, doi: 10.1055/s-0034-1395277.

2. H. Asresahegn, F. Tadesse, and E. Beyene, "Prevalence and associated factors of hypertension among adults in Ethiopia: A community based cross-sectional study," BMC Res. Notes, vol. 10, no. 1, pp. 1-8, 2017, doi: 10.1186/s13104-017-2966-1.

3. Y. Animut, A. T. Assefa, and D. G. Lemma, "Blood pressure control status and associated factors among adult hypertensive patients on outpatient follow-up at university of gondar referral hospital, northwest ethiopia: A retrospective follow-up study," Integr. Blood Press. Control, vol. 11, pp. 37-46, 2018, doi: 10.2147/IBPC.S150628.

4. N. Legese and Y. Tadiwos, "Epidemiology of hypertension in ethiopia: A systematic review," Integr. Blood Press. Control, vol. 13, pp. 135-143, 2020, doi: 10.2147/IBPC.S276089.

5. A. G. Demisse et al., "High burden of hypertension across the age groups among residents of Gondar city in Ethiopia: A population based cross sectional study," BMC Public Health, vol. 17, no. 1, pp. 110, 2017, doi: 10.1186/s12889-017-4646-4.

6. Zekewos A, Egeno T, and Loha E, "The magnitude of hypertension and its risk factors in southern Ethiopia: A community based study. PLoS ONE[revista en internet] 2019 [acceso 09 de noviembre del 2020]; 14(8): 1-12.," pp. 1-12, 2019, [Online]. Available: https://journals.plos.org/plosone/article/file? $i d=10.1371 /$ journal .pone. $0221726 \&$ type=printable.

7. M. Molla, "Systematic Reviews of Prevalence and Associated Factors of Hypertension in Ethiopia: Finding the Evidence," Sci. J. Public Heal., vol. 3, no. 4, p. 514, 2015, doi: 10.11648/j.sjph.20150304.19.

8. WHO, "GHO | By category Global Health Observatory Data," World Health Organization, 2020. .

9. S. S. Lim et al., "A comparative risk assessment of burden of disease and injury attributable to 67 risk factors and risk factor clusters in 21 regions, 1990-2010: A systematic analysis for the Global Burden of Disease Study 2010," Lancet, vol. 380, no. 9859, pp. 2224-2260, 2012, doi: 10.1016/S01406736(12)61766-8.

10. WHO, "Hypertension," 2019. https://www.who.int/news-room/fact-sheets/detail/hypertension (accessed Feb. 03, 2021).

11. WHO, "Global Brief on Hypertension: Silent Killer, Global Public Health Crisis," World Heal. Organ. 2013, vol. 24, no. 1, pp. 2-2, 2013, doi: 10.5005/ijopmr-24-1-2.

12. S. van de Vijver et al., "Status report on hypertension in Africa - Consultative review for the 6th Session of the African Union Conference of Ministers of Health on NCD's," Pan Afr. Med. J., vol. 16, pp. 1-17, 2013, doi: 10.11604/pamj.2013.16.38.3100.

13. F. Bonsa, E. K. Gudina, and K. W. Hajito, "Prevalence of hypertension and associated factors in Bedele Town, Southwest Ethiopia.," Ethiop. J. Health Sci., vol. 24, no. 1, pp. 21-26, 2014, doi: 10.4314/ejhs.v24i1.3.

14. D. Adeloye and C. Basquill, "Estimating the prevalence and awareness rates of hypertension in Africa: A systematic analysis," PLoS One, vol. 9, no. 8, 2014, doi: 10.1371/journal.pone.0104300. 
15. WHO, "WHO | Noncommunicable diseases country profiles 2011," World Heal. Organ., p. 209, 2011, [Online]. Available:

http://www.who.int/nmh/publications/ncd_profiles2011/en/index.html\#.UbNQMyMkAnQ.mendeley.

16. A. Misganaw, D. H. Mariam, and T. Araya, "The double mortality burden among adults in Addis Ababa, Ethiopia, 2006-2009," Prev. Chronic Dis., vol. 9, no. 4, pp. 2006-2009, 2012, doi: $10.5888 /$ pcd9.110142.

17. WHO, "2008-2013 Action Plan for the Global Strategy for the Prevention and Control of Noncommunicable Diseases," World Heal. Organ. 2008, 2013.

18. WHO, "Global status report on noncommunicable diseases," World Heal. Organ., p. 176, 2010.

19. W. Towers, "2014 Global Medical Trends-Survey Report," Middle East, 2014.

20. M. Kiber, M. Wube, H. Temesgen, W. Woyraw, and Y. A. Belay, "Prevalence of hypertension and its associated factors among adults in Debre Markos Town, Northwest Ethiopia: Community based cross-sectional study," BMC Res. Notes, vol. 12, no. 1, pp. 10-15, 2019, doi: 10.1186/s13104-0194431-9.

21. WHO, "Prevention of cardiovascular disease: Guidelines for assessment and management of cardiovascular risk," 2007.

22. WHO, "Prevention and Control of Noncommunicable Diseases: Guidelines for Primary Health Care in low-resource settings," WHO Libr. Cat. Data, pp. 1-70, 2012.

23. WHO, "Implementation tools Package of Essential Non-communicable disease interventions," Geneva World Heal. Organ., p. 210, 2013.

24. S. P. Choukem, A. P. Kengne, Y. M. Dehayem, N. L. Simo, and J. C. Mbanya, "Hypertension in people with diabetes in sub-Saharan Africa: Revealing the hidden face of the iceberg," Diabetes Res. Clin. Pract., vol. 77, no. 2, pp. 293-299, 2007, doi: 10.1016/j.diabres.2006.11.007.

25. H. N. Gouda et al., "Burden of non-communicable diseases in sub-Saharan Africa, 1990-2017: results from the Global Burden of Disease Study 2017," Lancet Glob. Heal., vol. 7, no. 10, pp. e1375e1387, 2019, doi: 10.1016/S2214-109X(19)30374-2.

26. S. Bushara, S. Noor, A. A. Ibraheem, W. Elmadhoun, and M. Ahmed, "Prevalence of and risk factors for hypertension among urban communities of North Sudan: Detecting a silent killer," J. Fam. Med. Prim. Care, vol. 5, no. 3, p. 605, 2016, doi: 10.4103/2249-4863.197317.

27. S. Huang et al., "COVID-19 patients with hypertension have more severe disease: a multicenter retrospective observational study," Hypertens. Res., vol. 43, no. 8, pp. 824-831, 2020, doi: 10.1038/s41440-020-0485-2.

28. S. Tamiru and F. Alemseged, "Risk Factors for Cardiovascular Diseases among Diabetic Patients In Southwest Ethiopia," Ethiop. J. Health Sci., vol. 20, no. 2, 2011, doi: 10.4314/ejhs.v20i2.69438.

29. F. Tesfaye, P. Byass, Y. Berhane, R. Bonita, and S. Wall, "Association of smoking and khat (Catha edulis Forsk) use with high blood pressure among adults in Addis Ababa, Ethiopia, 2006," Prev. Chronic Dis., vol. 5, no. 3, 2008. 
30. W. Getahun, T. Gedif, and F. Tesfaye, "Regular Khat (Catha edulis) chewing is associated with elevated diastolic blood pressure among adults in Butajira, Ethiopia: A comparative study," BMC Public Health, vol. 10, no. May 2015, 2010, doi: 10.1186/1471-2458-10-390.

31. $\mathrm{MOH}$, "Guidelines on Clinical and Programmatic Management of Major Non Communicable Diseases," 2016.

32. H. A. Shouhip, "Diabetes mellitus [Diabetes mellitus]," Rev. Bras. Med., vol. 62, no. SPEC. ISS., pp. 6071, 2005.

33. P. Harris, "The definition of heart failure," Eur. Heart J., vol. 4, no. 8, p. 600, 1983, doi: 10.1093/oxfordjournals.eurheartj.a061529.

34. WHO, "Global Tuberculosis Control-WHO Report 2010," 2010.

35. P. McCullagh and J. A. Nelder, "Generalized Linear Models, 2nd Edn.," Applied Statistics, vol. 39, no. 3. p. 385,1990 , doi: $10.2307 / 2347392$.

36. A. Agresti, An introduction to categorical data analysis (2nd edn). Alan Agresti, John Wiley \& Sons, Inc., Hoboken, New Jersey, 2007. No. of Pages: 400. Price: \$100.95. ISBN: 978-0-471-22618-5, vol. 28, no. 11. 2007.

37. Newson, "Generalized Linear Models Link Function The logistic equation is stated in terms of the probability that," 2016.

38. D. W. Hosmer and S. Lemeshow, "Applied Logistic Regression - David W. Hosmer, Jr., Stanley Lemeshow - Google Books," 1989. https://books.google.com.et/books/about/Applied_Logistic_Regression.html? id=PoORLQ7USIMC\&redir_esc=y (accessed Feb. 03, 2021).

39. A. A. Mansour, "Prevalence and Control of Hypertension in Iraqi Diabetic Patients: A Prospective Cohort Study," Open Cardiovasc. Med. J., vol. 6, no. 1, pp. 68-71, 2012, doi: $10.2174 / 1874192401206010068$.

40. A. Y. Mengesha, "Hypertension and related risk factors in type 2 diabetes mellitus (DM) patients in Gaborone City Council (GCC) clinics, Gaborone, Botswana.," Afr. Health Sci., vol. 7, no. 4, pp. 244245, 2007.

41. F. Nouh, M. Omar, and M. Younis, "Prevalence of Hypertension among Diabetic Patients in Benghazi: A Study of Associated Factors," Asian J. Med. Heal., vol. 6, no. 4, pp. 1-11, 2017, doi: 10.9734/ajmah/2017/35830.

42. A. D. Colosia, R. Palencia, and S. Khan, "Prevalence of hypertension and obesity in patients with type 2 diabetes mellitus in observational studies: A systematic literature review," Diabetes, Metab. Syndr. Obes. Targets Ther., vol. 6, pp. 327-338, 2013, doi: 10.2147/DMSO.S51325.

43. S. S. Yoon, V. Burt, T. Louis, and M. D. Carroll, "Hypertension among adults in the United States, 20092010.," NCHS Data Brief, no. 107, pp. 1-8, 2012.

44. S. K. Sharma et al., "Prevalence of hypertension, obesity, diabetes, and metabolic syndrome in Nepal," Int. J. Hypertens., vol. 2011, 2011, doi: 10.4061/2011/821971. 
45. A. B. Zeru and M. A. Muluneh, "Admission and inpatient mortality of hypertension complications in Addis Ababa," Integr. Blood Press. Control, vol. 13, pp. 103-110, 2020, doi: 10.2147/IBPC.S268184.

\section{Figures}

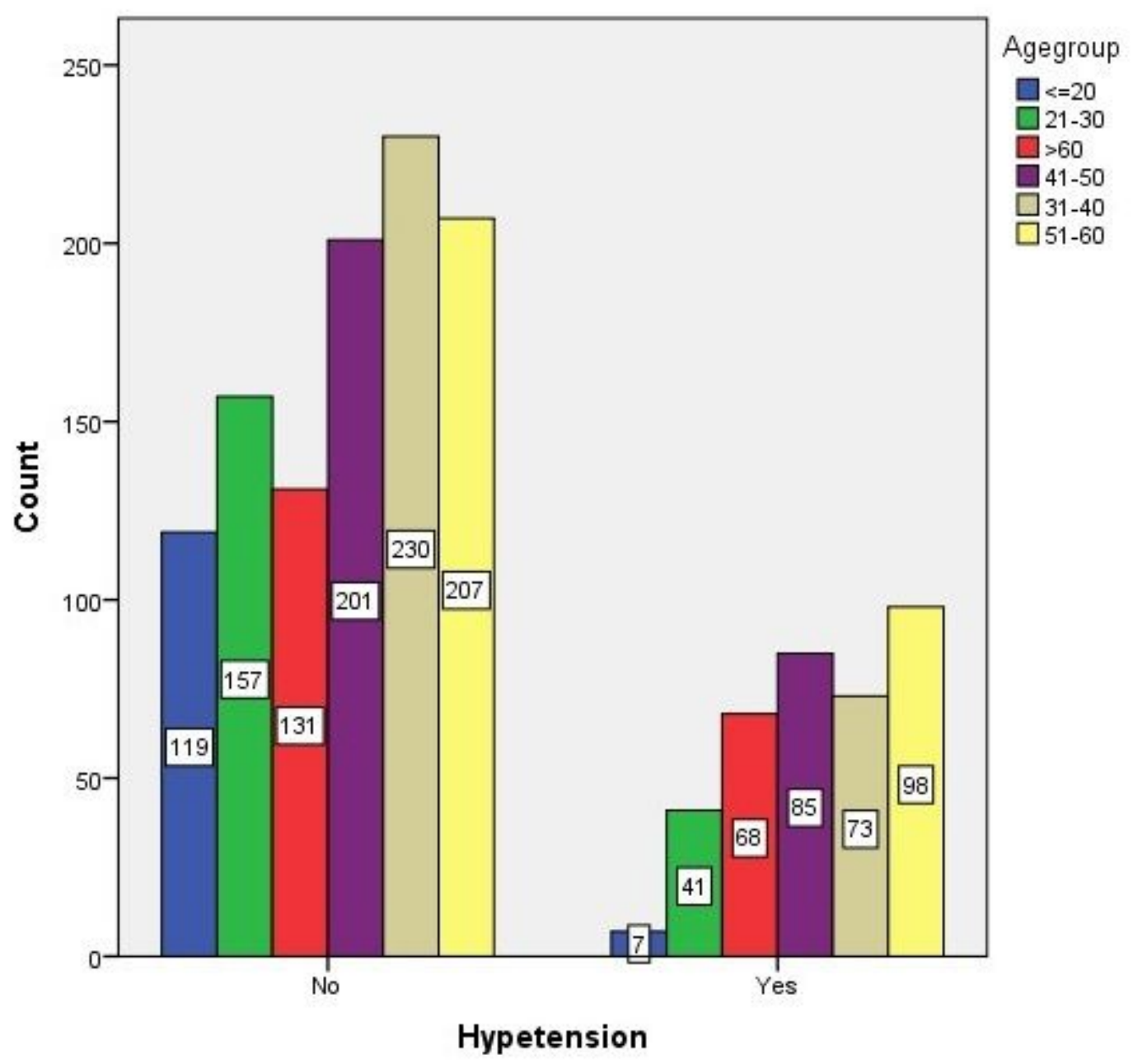

Figure 1

Age conveyance of respondents conceded at Haramaya Healing center for the hypertensive case

\section{Supplementary Files}

This is a list of supplementary files associated with this preprint. Click to download.

- GraphicalAbstractimage.docx 